Supporting Information for:

\title{
Cathodic Electrodeposition of Mixed Molybdenum-Tungsten Oxides from Peroxo-Polymolybdotungstate Solutions
}

Lilia Kondrachova, Benjamin P. Hahn, Ganesh Vijayaraghavan, Ryan D. Williams and Keith J. Stevenson*

Department of Chemistry and Biochemistry, Center for Nano- and Molecular Science and Technology, Texas Materials Institute, University of Texas at Austin, Austin, Texas 78712

*Email: stevenson@mail.cm.utexas.edu 

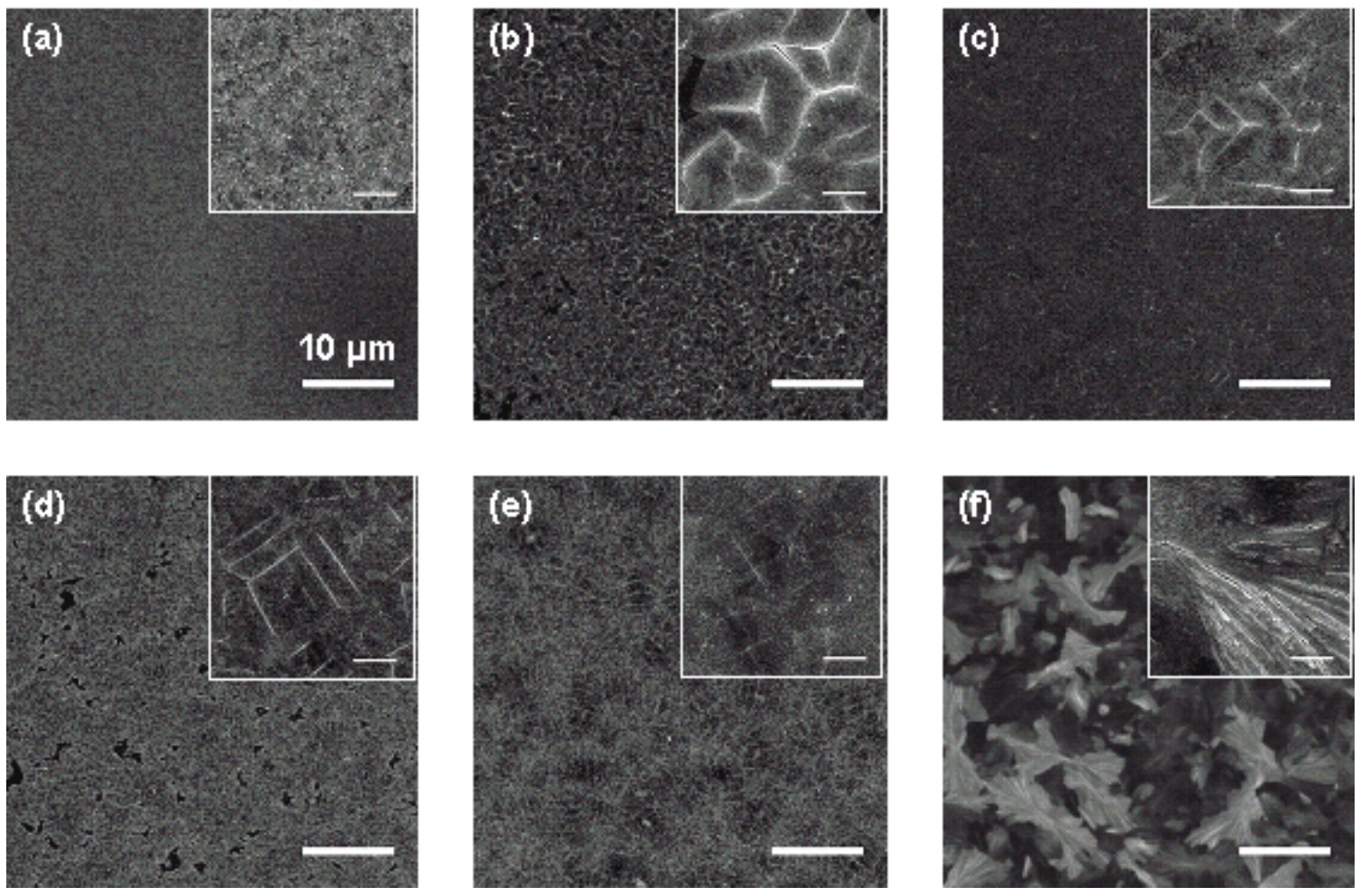

Figure S1. Scanning electron micrographs ( $50 \mu \mathrm{m}$ x $50 \mu \mathrm{m}$ area) of (a) $\mathrm{WO}_{3}$, (b) $\mathrm{Mo}_{0.42} \mathrm{~W}_{0.58} \mathrm{O}_{3}$, (c) $\mathrm{Mo}_{0.55} \mathrm{~W}_{0.45} \mathrm{O}_{3}$, (d) $\mathrm{Mo}_{0.55} \mathrm{~W}_{0.41} \mathrm{O}_{3}$, (e) $\mathrm{Mo}_{0.73} \mathrm{~W}_{0.27} \mathrm{O}_{3}$, and (f) $\alpha-/ \beta$ $\mathrm{MoO}_{3}$ electrodeposited at $-0.35 \mathrm{~V}$ on ITO glass substrate and sintered in air at $250{ }^{\circ} \mathrm{C}$ for $2 \mathrm{~h}$. Inset: higher resolution ( $5 \mu \mathrm{m} \times 5 \mu \mathrm{m}$ area) images of the representative films showing local microstructure. 